Article

\title{
Neuronless Knowledge Processing in Forests
}

\author{
Aviv Segev ${ }^{1, *}$, Dorothy Curtis ${ }^{2}$, Christine Balili ${ }^{3}$ and Sukhwan Jung ${ }^{1}$ \\ 1 Department of Computer Science, University of South Alabama, Mobile, AL 36688, USA; \\ shjung@southalabama.edu \\ 2 Computer Science and Artificial Intelligence Laboratory, Massachusetts Institute of Technology, Cambridge, \\ MA 02139, USA; dcurtis@csail.mit.edu \\ 3 Knowledge Service Engineering, Korea Advanced Institute of Science and Technology, Daejeon 305-701, \\ Korea; ccbalili@kaist.ac.kr \\ * Correspondence: segev@southalabama.edu
}

Received: 11 March 2020; Accepted: 1 April 2020; Published: 5 April 2020

Featured Application: The ability of a network of trees to process information like a biological neural network and make decisions regarding resource usage is unperceived. We show that the network between trees is used for knowledge processing to implement decisions prioritizing the forest over a single tree regarding resource optimization. When there is a resection of a network of trees in a forest, a trail, each network part will try optimizing its overall access to light resources, represented by canopy tree coverage, independently. We analyzed 323 forests in different US locations. Following resection, forest activity showed behavior similar to neuron activity behavior. We anticipate other systems exist in nature where basic knowledge processing for resource usage is performed by components other than neurons.

\begin{abstract}
Neurons are viewed as the basic cells that process and transmit information. Trees and neurons share a similar structure and neurotransmitter-like substances. No evidence for structures such as neurons, synapses, or a brain has been found inside plants. Consequently, the ability of a network of trees to process information in a method similar to that of a neural network and to make decisions regarding the usage of resources is unperceived. We show that the network between trees is used for knowledge processing to implement decisions that prioritize the forest over a single tree regarding forest use and optimization of resources, similar to the processes of a biological neural network. We found that when there is resection of a network of trees in a forest, namely a trail, each network part will try optimizing its overall access to light resources, represented by canopy tree coverage, independently. This was analyzed in 323 forests in different locations across the US where forest resection is performed by trails. Our results demonstrate that neuron-like relations can occur in a forest knowledge processing system. We anticipate that other systems exist in nature where the basic knowledge processing for resource usage is performed by components other than neurons.
\end{abstract}

Keywords: knowledge processing; trees; neuron activity; forest network

\section{Introduction}

Neurons are viewed as the basic cells that process and transmit information. Trees and neurons share similar structure and neurotransmitter-like substances [1,2]. No evidence for structures such as neurons, synapses, or a brain has been found inside plants [3]. Signal processing by trees has been known since Salix sitchensis trees were found to be sensitive to and respond to signals generated by trees attacked by tent caterpillars and webworms [4]. Interplant communication can occur from leaves of one species of plant to leaves of another species to activate the expression of defensive genes [5]. $\mathrm{N}$-(17-hydroxylinolenoyl)-L-glutamine was found to be a key compound in communication between 
leaves of corn seedlings eaten by beet armyworms and in calls for help to the enemy of their enemy, parasitic wasps [6]. Furthermore, species in ecological communities show the ability to build complex webs of communication based on plant fungus $[7,8]$.

Communication of plants through airborne signals has been analyzed $[9,10]$. In addition, plants have memory defined by reversible changes in behavior (plasticity) that has been altered by experience [11]. Previous work has shown changes in neural substrates of memory [12] based on predictions of rewarding events using adaptive optimization control [13]. However, there is a lack of knowledge about the mechanisms that lead to plant communication that are beneficial for both plant emitter and receiver [10].

A roadmap towards a functional paradigm for learning and memory in plants has been proposed [14]. From the seven requirements proposed to substantiate plant learning and memory, one aspect included information processing which was in initial stages and needed additional clarification. Another requirement aspect proposed was independent internal representation, which is currently theoretical and needs further investigation. Here, instead of viewing each plant as an independent mechanism, we view the forest as a system that is processing information and has representation of the knowledge being processed.

We show how viewing a forest as a network rather than as separate tree entities can help explain the benefit of communication as resource optimization. It is suggested that each tree's goal of survival is directed by the forest trying to optimize its resources, which in our case is access to sunlight. Comparison of a forest network to a neural network shows interesting similarities in both the physical structure and some of the functional properties of both networks.

We define Knowledge Processing as the analysis of information intended to try to optimize the use of available resources. Animals are viewed as having the ability to process knowledge at different levels in order to use their available resources. To bypass the philosophical argument of whether animals or trees "think", we analyze the use of resources needed to survive. In the case of animals, neuron brain activity allows the processing of the knowledge of available resources. Since trees lack neurons but can build a communication network [15], their use of the resources required for survival, including light, nutrients, and water, can be analyzed. We chose to analyze the communication between trees in a forest that tries to optimize the use of light.

The analysis is inspired by epilepsy resection, the action performed on neurons when they exhibit high neuron activity. In epilepsy resection, a part of the brain, a set of neurons, is removed to allow the neurons residing in the surrounding area to become less active and resume normal neuron activity [16]. Here we try to imitate the idea behind this procedure and look at forests where a section of trees has been removed. The idea is that resection causes nearby neurons (trees) to become less active, or rather, less efficient at processing knowledge. This means "resume normal activity" in hyper-acting neurons, but "falls down to abnormal activity" in trees. We analyze trees on both sides of an area in the forest which was "surgically" removed by humans-a trail. We look at the behavior of trees and analyze the change of the use of light as the distance from the trails increases.

When the forest canopy increases near the resection, it increases logarithmically as the distance from the resection increases. Some exceptions to this phenomenon showed forest structure similar to the neuron semi-sphere shape proliferate structure occurring in brain tumors. The results show that neuron-like relations can occur in a forest knowledge processing system.

The similarity between human neurons transmitting knowledge and forest trees transmitting knowledge can be seen from the network structure and the network behavior. The ability to process the knowledge regarding the available resources while optimizing their use appears to be similar. Furthermore, each processing unit, neuron or tree, seems to prioritize the resource needs of the network rather than its own needs.

The importance of the results is in the ability to analyze neuron-like behavior in an environment which processes knowledge much slower than human neurons. The forest environment, representing 
nature-inspired knowledge processing, has similar characteristics to brain neuron processing but is easier to manipulate and control.

\section{Methods}

ArcGIS [17], a spatial analysis tool, was used for canopy coverage and distance from trail calculations. The set of sampled points representing changes in landscape was used to observe the continuity and variability of the data across a surface using interpolation tools. Deterministic and geo-statistical techniques were used for interpolation. Inverse Distance Weight (IDW) and Spline are deterministic techniques based on the extent of similarity of cells. Kriging is a geo-statistical interpolation technique.

IDW is based on a linear weighted combination of a sample of points. The weight is assigned as a descending function when the distance of the input point to the cell location is growing.

$$
\hat{Z}\left(s_{0}\right)=\sum_{i=1}^{N} \lambda_{i} Z\left(s_{i}\right)
$$

$\hat{Z}\left(s_{0}\right)$ is the predicted value for given location $s_{0} . N$ is the number of measured points near the predicted location. $\lambda_{i}$ are weights assigned to each measured point used. The weights value decreases as the distance increases. $Z\left(s_{i}\right)$ is the measured value at location $s_{i}$.

$$
\lambda_{i}=d_{i 0}^{-p} / \sum_{i=1}^{N} d_{i 0}^{-p} \sum_{i=1}^{N} \lambda_{i}=1
$$

As distance increases, the weight is reduced by a factor of p. $d_{i 0}$ is the distance between prediction location $s_{0}$ and each measured location $s_{i}$. The optimal $p$ value is determined by minimizing the root-mean square prediction error (RMSPE). The RMSPE is the statistic that is calculated from cross-validation where each measured point is removed and compared to the predicted value of the location. The IDW aims at identifying the value that produces the minimum RMSPE.

Kriging performs statistical interpolation by fitting a function to a specified number of points with a specified radius to determine the output value for each location. Kriging provides information on the spatial autocorrelation of the dataset, the forest canopy coverage. We use the spatial resolution of a $30 \mathrm{~m}^{2}$ cell covered by tree canopy. Fitting and loss of tree canopy coverage values were produced using a Random Forests regression. It assumes the distance between sample points reflects a spatial correlation that explains the variation in the surface.

$$
Z(s)=\mu(s)+\varepsilon(s)
$$

where $Z(s)$ is the value for location $s, \mu(s)$ is the deterministic trend, and $\varepsilon(s)$ are the random correlated errors.

$$
\mu(s)=\beta_{0}+\beta_{1} x+\beta_{2} y+\beta_{3} x^{2}+\beta_{4} y^{2}+\beta_{5} x y
$$

representing the second-order polynomial trend surface linear regression on $\mathrm{x}$ and $\mathrm{y}$ coordinates.

Spline estimates values by minimizing the overall surface curvature. This is based on a smooth surface that passes through the input points.

\section{Results}

Forest canopy tree coverage degradation and regeneration in areas surrounding trails were analyzed in 19 locations of national forests across the US. We sampled 2802 trails in these forests. The total number of trails sampled in each forest ranged from 6 to 825 per forest.

The tree canopy coverage of each trail is based on data from the USGS/MRLC National Land Cover Database [18]. Tree canopy coverage is available for 2011 (13.2 GB) for the entire US. Each spatial 
resolution represents the proportion of a $30 \mathrm{~m}^{2}$ cell covered by tree canopy. Tree canopy coverage values were produced using a Random Forests regression algorithm. ArcMap was used as a Geographical Information System (GIS) to analyze the different information layers, placing the trails on top of the tree canopy coverage (Figure 1A). Next, we analyzed the canopy coverage change range from each trail to the distance of $450 \mathrm{~m}$ from the trail (Figure 1B). Around each trail a series of rings was created. Each ring represents an additional growing distance of $45 \mathrm{~m}$ from the center of the trail. The average canopy coverage at a fixed time was analyzed for each ring.

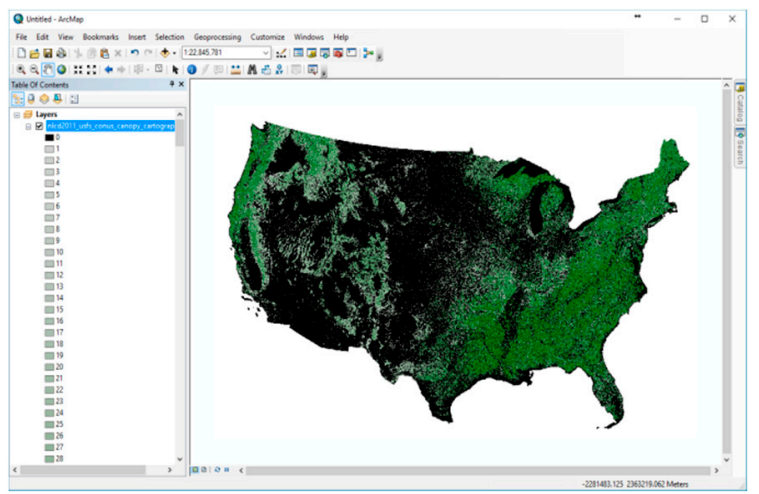

(A)

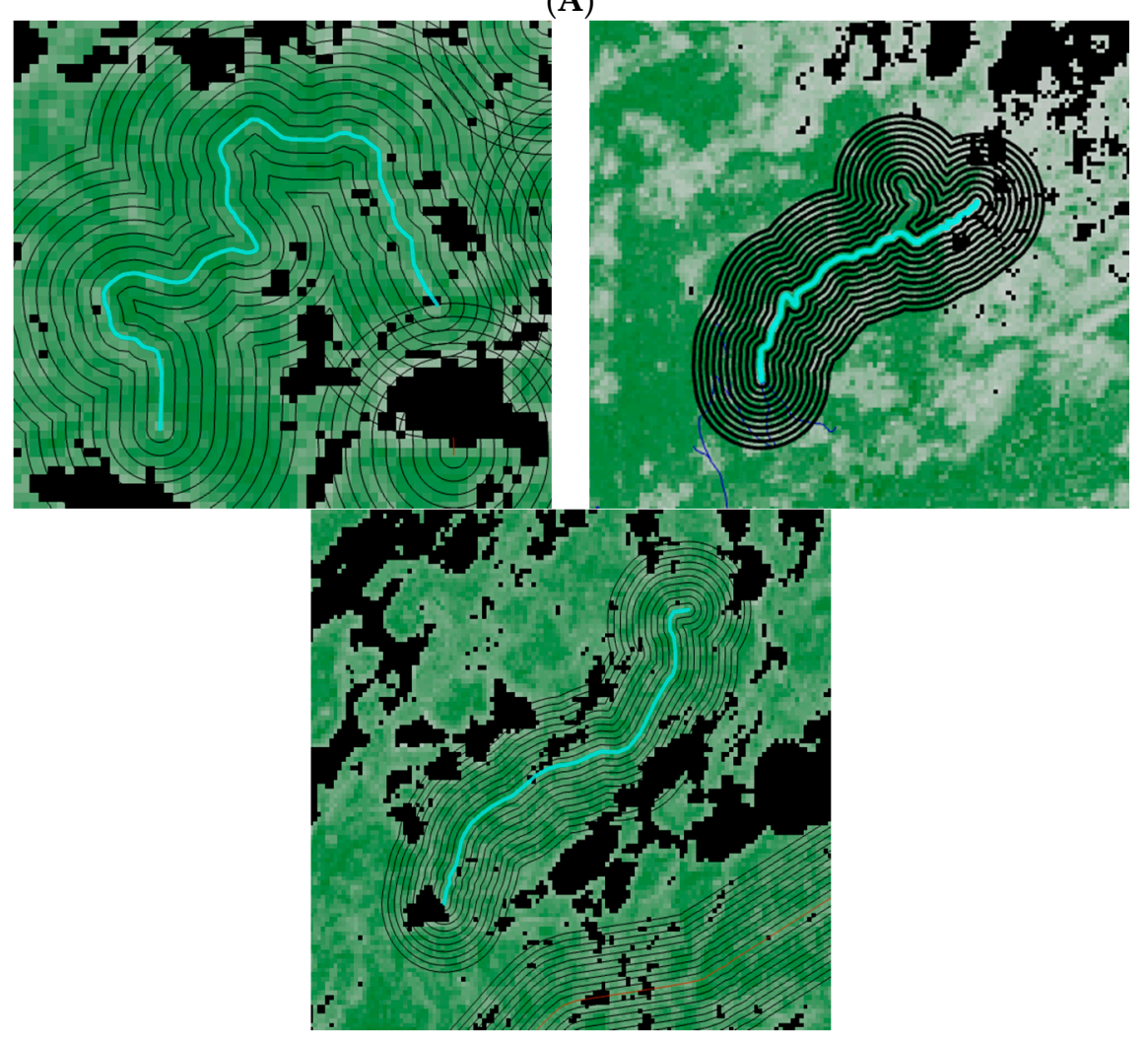

(B)

Figure 1. Tree canopy across the US (A). Tree canopy coverage surrounding forest trails (B). The light blue-green line is the actual trail. The surrounding black rings around the trail represent increasing distances from the trail center, $45 \mathrm{~m}$ apart. The green map layout represents canopy coverage per location, image pixel-30 $\mathrm{m}^{2}$, calculated based on satellite imagery. The darker the shade of green, the greater the canopy coverage is. For each ring extending the distance around the trail, the average green shading was calculated. Black areas in the map represent areas where no canopy was identified, such as bodies of water and cliffs. The overlapping influence of effects from nearby trails was also analyzed, as can be seen from other coinciding rings from other trails. 
The total number of trails analyzed that exhibited at least $10 \%$ change in canopy tree coverage within the $450 \mathrm{~m}$ proximal was 323 . The number of trails with the $10 \%$ change varied in each national forest from 1 to 96 . Trails with high canopy change were selected to analyze the network structure after resection. Table 1 presents the sampled trail distribution in forests across the US. The overall results show that $86.51 \%$ of the cases analyzed present increased canopy coverage as the distance from the resection increases. The results can be viewed as knowledge processing in forests based on the consistency between tree network resection and canopy coverage as distances of up to $450 \mathrm{~m}$. While influence on the nearby trees can be attributed to people walking on the trails, trees at a further distance from the trail should not be influenced by the trail themselves, and this absence of a direct influence was confirmed in multiple locations. The attempt of the forest to optimize the use of light resources through canopy coverage can be viewed as knowledge processing using the trees as a network.

Table 1. Displays the forests analyzed across the US with number of forest trails showing an increase of at least $10 \%$ of the canopy following the resection of the forest (trails). The overall results show that $86.51 \%$ of the cases analyzed are consistent with increased canopy coverage as the distance from the resection increases. The results show the correspondence of increased distance with increased canopy coverage.

\begin{tabular}{ccccc}
\hline State & National Forest & $\begin{array}{c}\text { Forest Trails } \\
\text { (Number of Trails) }\end{array}$ & $\begin{array}{c}\mathbf{2 1 0} \text { \% Canopy } \\
\text { Increase (Number } \\
\text { of Trails) }\end{array}$ & $\begin{array}{c}\text { Increased Distance-Canopy } \\
\text { Correlation Correspondence } \\
\text { (Number of Trails) }\end{array}$ \\
\hline Pennsylvania & Allegheny & 73 & 10 & 9 \\
Idaho & Boise & 160 & 7 & 7 \\
Wyoming & Bridger-Teton & 222 & 36 & 34 \\
Idaho & Clearwater & 825 & 96 & 3 \\
California & Eldorado & 137 & 6 & 21 \\
Montana & Flathead & 186 & 27 & 20 \\
Florida & Florida & 83 & 25 & 1 \\
Montana & Lolo & 6 & 1 & 20 \\
California & Mendocino & 111 & 21 & 3 \\
California & Modoc & 21 & 3 & 12 \\
Oregon & Mt Hood & 199 & 14 & 2 \\
Nebraska & Nebraska & 21 & 2 & 18 \\
Idaho & Nez Perce & 165 & 18 & 22 \\
Washington & Okanogan-Wenatchee & 306 & 28 & 2 \\
Washington & Olympic & 54 & 6 & 3 \\
Colorado & Rio Grande & 30 & 3 & 6 \\
California & Sierra & 36 & 6 & 10 \\
California & Six Rivers & 69 & 11 & 2 \\
Oregon & Umpqua & 98 & 3 & 289 \\
\hline
\end{tabular}

Forest resection by trails is analyzed in multiple locations across the US. From all the occurrences of at least $10 \%$ increase in canopy from the trail, examples of three locations are presented (Figure 2A,C,E): Florida, Allegheny, and the Rio Grande National Forests. Additional locations appear in the Supplementary Information (Figures S1 and S2). The canopy coverage was evaluated at an additional growing distance of $45 \mathrm{~m}$ surrounding the trail. The mean value \pm standard error of the mean (s.e.m.) is displayed. The results show dieback away from the trail center which continues to a distance of $450 \mathrm{~m}$. 


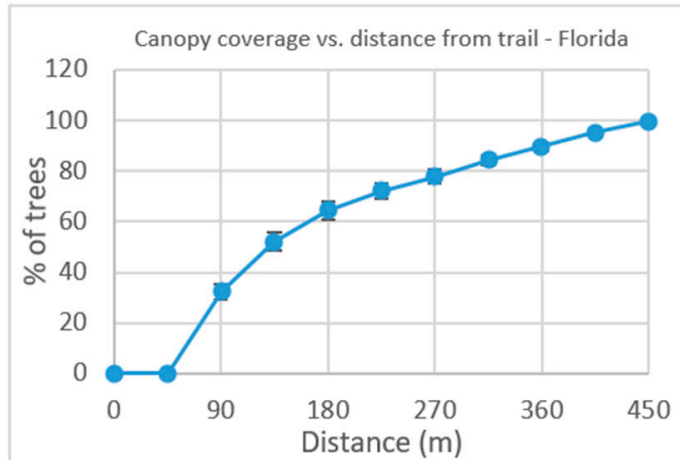

(A)

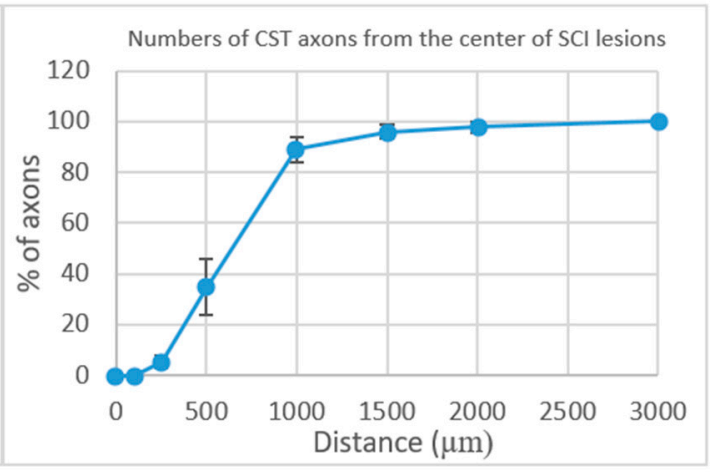

(B)

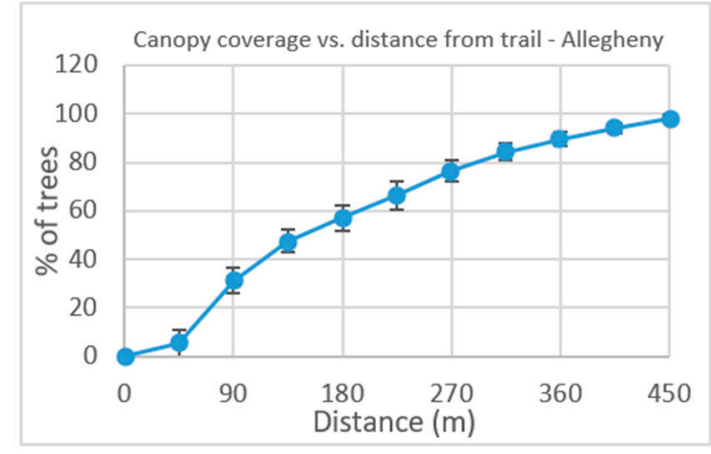

(C)

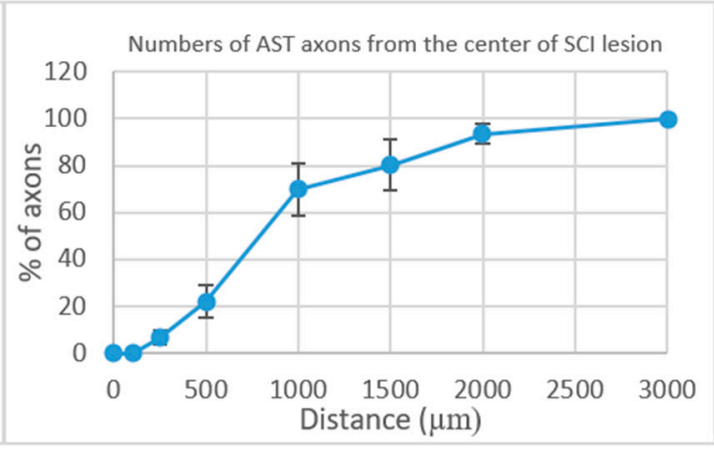

(D)

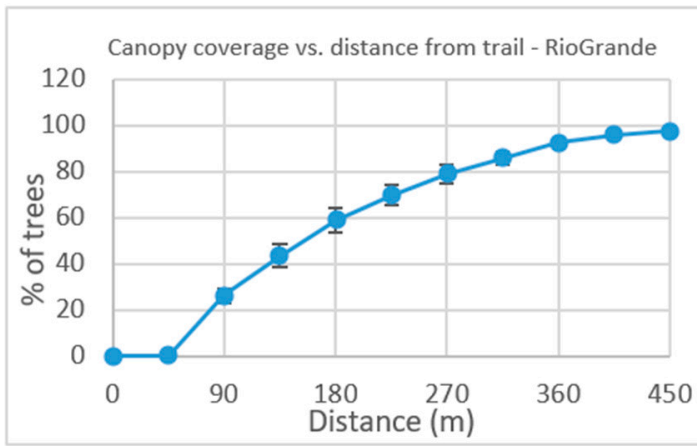

(E)

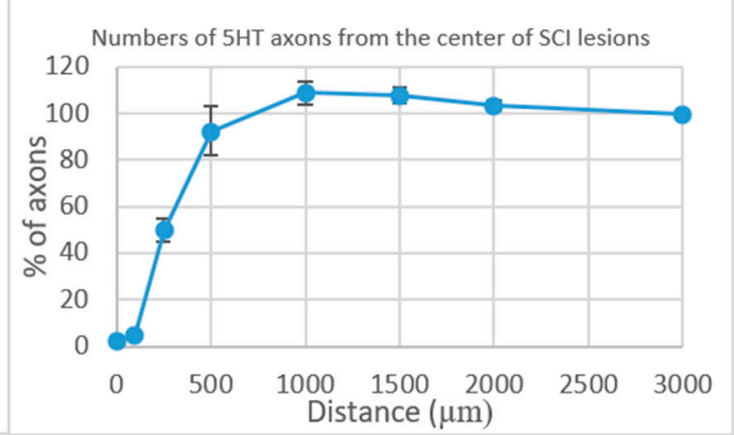

$(\mathbf{F})$

Figure 2. (A,C,E), Forest resection performed by trails. Numbers (means \pm s.e.m.) of trees at Florida National Forest (A), Allegheny National Forest (C), and Rio Grande National Forest (E) canopy coverage at various distance from trail lesion center as percentage of total canopy coverage at $450 \mathrm{~m}$ proximal. (B,D,F), Severe crush spinal cord injuries (SCI) performed on mice [19]. Numbers (means \pm s.e.m.) of descending corticospinal tract (CST) (B), ascending sensory tract (AST) (D), and descending serotonergic $(5 \mathrm{HT})$ tract $(\mathbf{F})$ axons at various distances from the SCI lesion center as a percentage of the total number of axons present $3 \mathrm{~mm}$ proximal (Figure S3).

Forest resection by trails was compared to neuron resection. The neuronal comparison values are taken from Anderson et al. [19], who performed in their research on severe crush spinal cord injuries (SCI) in wild-type mice. Following the severe crush SCI, dense astrocytic scars were formed in the mice over a period of two weeks and remained until eight weeks. The consequence of the astrocyte scar formation on axon regeneration was analyzed by three evaluation measurements: descending corticospinal tract (CST), ascending sensory tract (AST), and descending serotonergic (5HT) tract. As a result of the severe SCI in the mice, transected CST, AST, and 5HT axons exhibit dieback away from the lesion center (Figure 2B,D,F). 
The results of the canopy tree coverage as the distance from the trail extends compared to the results of the neuron axon coverage as the distance from the lesion center extends show a high level of similarity. The expected results of a set of trees acting independently, attempting to maximize their canopy coverage, would yield different results from a growing logarithmic graph consistently appearing in all locations. We can infer from the results that the trees, after resection, attempt to form two independent entities, each trying to perform network knowledge processing to optimize their light resource usage. The alternative explanation of damage by trail travelers which expands past the trail area on both sides would not explain the effect reaching a distance of $450 \mathrm{~m}$ on both sides of each trail in all the cases described. A possible explanation is the communication of the tree network trying to recover from the trail resection while reformatting the tree canopy coverage in an attempt to maximize the light coverage as a network of trees.

The cases in which the forests did not exhibit an increase in the canopy coverage as the distance from the trails increased (Table 1, 13.49\% of the cases) were analyzed manually for each case. Some of the cases had multiple reasons. The most common reason for the inconsistent increase included large bodies of water such as lakes or rivers within the vicinity of the trails ( 25 cases). Other reasons included manmade forest-empty areas used for agriculture, residences, or roads (nine cases). Another reason that explained the inconsistency was a sharp geographical drop in height, which can be defined as a mountain cliff, which is another unfavorable environment for tree canopies (four cases).

Past studies on tree regeneration in felling and natural tree fall disturbances showed similar results appearing in logging areas [20]. The research found that forest gap area and canopy openness were positively related in both logging gap areas and natural gap areas. The results stated that the lack of response to canopy openness in natural gaps was likely a result of relatively low levels of understory and substrate disturbance coupled with the absence of large natural gaps with high canopy openness. These results show that direct forest gap due to logging does effect the canopy. However, our work shows a possible explanation for both the increased damage and the regrowth pattern in both the natural and logging gaps.

Other work on areas of disturbed and residual stand damage following logging in a Bolivian tropical forest [21], and damage and carbon export by reduced-impact logging in southern Amazonia [22], also showed logging as an important factor in impacting canopy openness-which is similar to our work and supports our results. An assessment of canopy damage and ground disturbance in skid trails and tree-fall gaps was performed. In both of these cases, the emphasis in the analysis was on directly impacted trees. Our results show the damage can be far deeper than seen in these previous works and the process of recovery of the forest is similar to the recovery of a neural network from an error value. In the neural network the process is known as readjusting the weights of the neural network.

\section{Discussion}

An additional interesting increase in canopy coverage that is inconsistent with the distance from the trail resection is due to mountain rock or land formation ( 3 cases). The tree formation in these cases seems to be concentrated in specific spherical areas, with few trees in the surrounding circumference. For a forest in growth distress, the land formation limiting forest growth can be compared to brain cancer (Figure 3). The trees form a spherical canopy growth pattern (Figure 3A-E), which displays some similarities to neurons in a brain tumor $[23,24]$. 


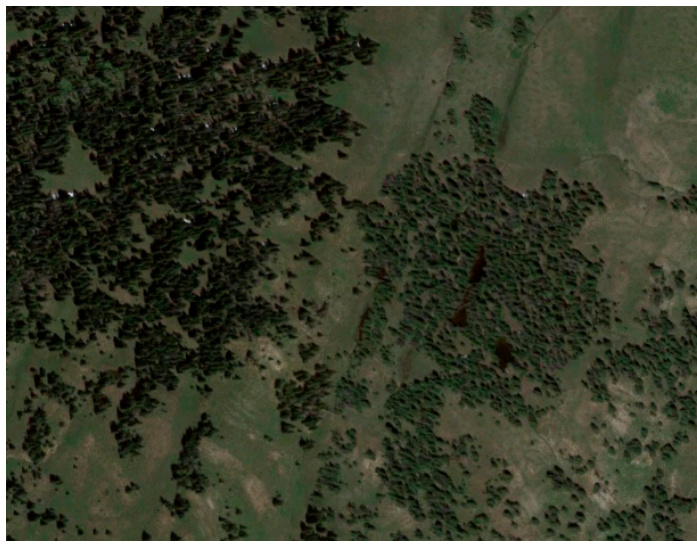

(A)

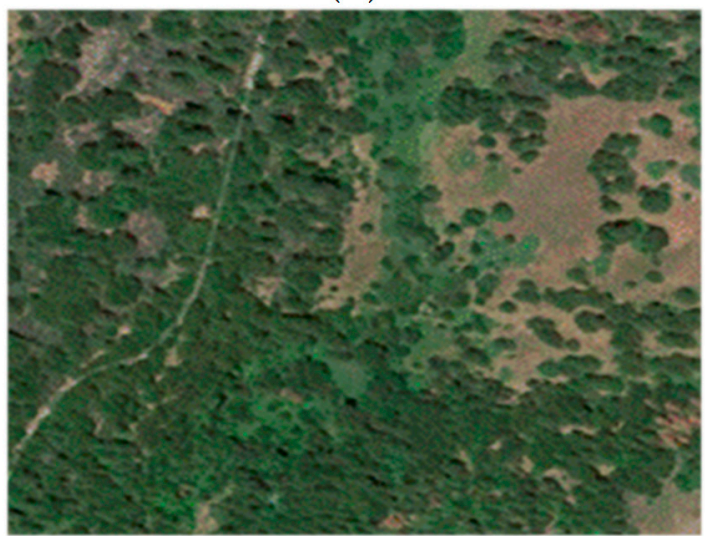

(C)

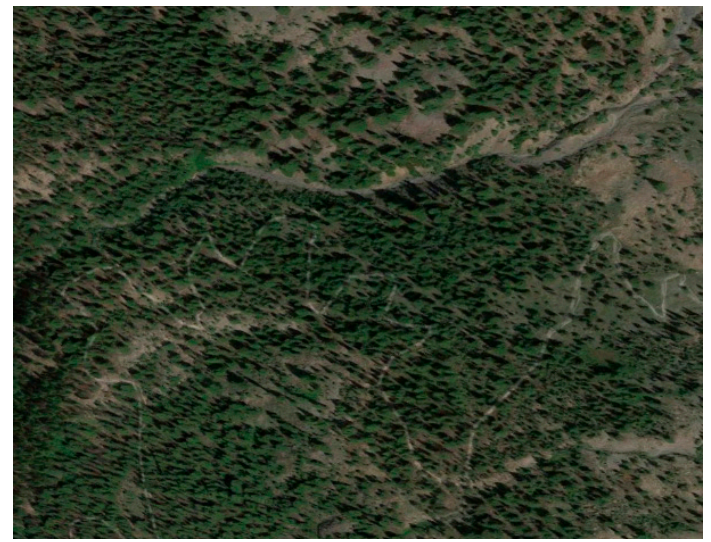

(B)

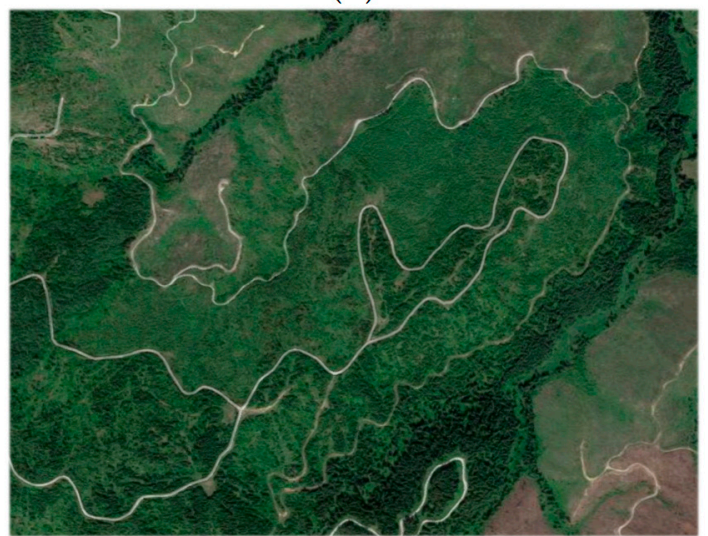

(D)

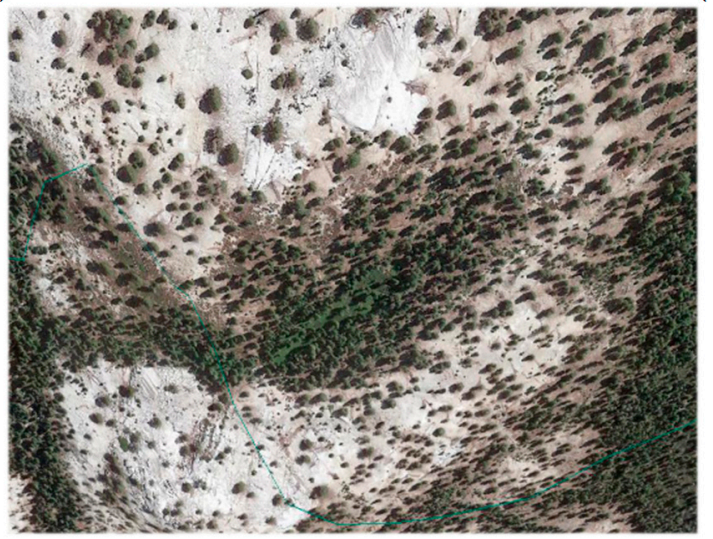

(E)

Figure 3. Both brain tumor cells and trees proliferate in a nonadherent semi-sphere shape, whereas neuron cells and forest areas that adhere to the pattern do not proliferate and do not form semi-spheres. Forest trees which display an opposite growth pattern to the identified tree formation in Bridger Teton National Forest (A), Okanogan-Wenatchee National Forest (B), Eldorado National Forest (C), Clearwater National Forest (D), and Rio Grande National Forest (E).

We show that when resection of forests occurs, each part of the forest tries to optimize its light resources, measured by canopy coverage independently. Therefore, the forests can be viewed as a knowledge processing network as opposed to just a communication network. The trees in the forest attempt to maximize their use of resources; in our case, only the resource of light was analyzed. The knowledge processing network of trees in the forest resembles the activity of neurons working in the brain system. Other resource usage of trees can be analyzed to examine whether the use of 
nutrients and water also involves a neural network like pattern. Furthermore, knowledge processing without neurons might appear in other systems in nature.

\section{Conclusions}

Many recent artificial intelligence models rely more on neural networks. These models have been proven to be more successful than some of the other directions of artificial intelligence. The success of the neural network models in the field of computing leads to the question of whether knowledge processing is based on neural networks. Another issue that arises is how common neural network knowledge processing is in nature-inspired systems.

The results show that trees use mechanisms which could be interpreted as similar to neural network knowledge processing. The communication between neurons in the brain is similar to the communication of knowledge in forests when trying to optimize a decision. In our study, the results show the optimization of maximizing the canopy over the entire forest as a process of sharing knowledge between all trees. Each interference in one part of the network is transmitted, and the entire network attempts to overcome the loss and reoptimize the use of resources, in this case sunlight. Similarly, neurons in the brain can be viewed as trying to optimize the use of available resources.

The results can lead to the philosophical question of how unique knowledge processing in the human brain is if similar knowledge processing happens to commonly appear in nature. The use of models which can be defined as equivalent to neural network processing by trees might be just one example of nature-inspired knowledge processing behavior. Other neural network knowledge processing models might be common, and therefore the knowledge processing which we call "thinking" might be widely used by processing mechanisms other than human ones.

Supplementary Materials: The following are available online at http://www.mdpi.com/2076-3417/10/7/2509/s1, Figures S1, S2: Forest resection performed by trails, Figure S3: Data of severe crush spinal cord injuries (SCI) performed on mice. Data availability: Data S1-S6.

Author Contributions: A.S. conceived the idea and the study. A.S., D.C., C.B., S.J. designed the experiments. A.S., C.B., S.J. performed the experiments. A.S., D.C., C.B., S.J. analyzed the data. A.S. wrote the manuscript. All authors have read and agreed to the published version of the manuscript.

Funding: This research received no external funding.

Conflicts of Interest: The authors declare no conflict of interest

\section{References}

1. Paciorek, T.; Zažímalová, E.; Ruthardt, N.; Petrášek, J.; Stierhof, Y.-D.; Kleine-Vehn, J.; Morris, D.A.; Emans, N.; Jürgens, G.; Geldner, N. Auxin inhibits endocytosis and promotes its own efflux from cells. Nature 2005, 435, 1251-1256. [CrossRef] [PubMed]

2. Trewavas, A. Plant intelligence: Mindless mastery. Nature 2002, 415, 841. [CrossRef] [PubMed]

3. Alpi, A.; Amrhein, N.; Bertl, A.; Blatt, M.R.; Blumwald, E.; Cervone, F.; Dainty, J.; de Michelis, M.I.; Epstein, E.; Galston, A.W.; et al. Plant neurobiology: No brain, no gain? Trends Plant Sci. 2007, 12, 135-136. [CrossRef] [PubMed]

4. Rhoades, D.F. Responses of alder and willow to attack by tent caterpillars and webworms: Evidence for pheromonal sensitivity of willows. In Plant Resistance to Insects 55-68; ACS: Washington, DC, USA, 1983.

5. Farmer, E.E.; Ryan, C.A. Interplant communication: Airborne methyl jasmonate induces synthesis of proteinase inhibitors in plant leaves. Proc. Natl. Acad. Sci. USA 1990, 87, 7713-7716. [CrossRef] [PubMed]

6. Alborn, H.T.; Turlings, T.C.J.; Jones, T.H.; Stenhagen, G.; Loughrin, J.H.; Tumlinson, J.H. An elicitor of plant volatiles from beet armyworm oral secretion. Nature 1997, 276, 945-949. [CrossRef]

7. Toju, H.; Guimarães, P.R.; Olesen, J.M.; Thompson, J.N. Assembly of complex plant-fungus networks. Nat. Commun. 2014, 5, 5273. [CrossRef]

8. Steidinger, B.S.; Crowther, T.W.; Liang, J.; van Nuland, M.E.; Werner, G.D.A.; Reich, P.B.; Nabuurs, G.J.; de-Miguel, S.; Zhou, M.; Picard, N.; et al. Climatic controls of decomposition drive the global biogeography of forest-tree symbioses. Nature 2019, 569, 404-408. [CrossRef] 
9. Arimura, G.; Ozawa, R.; Shimoda, T.; Nishioka, T.; Boland, W.; Takabayashi, J. Herbivory-induced volatiles elicit defence genes in lima bean leaves. Nature 2000, 406, 512-515. [CrossRef]

10. Heil, M.; Karban, R. Explaining the evolution of plant communication by airborne signals. Trends Ecol. Evol. 2010, 25, 137-144. [CrossRef]

11. Karban, R. Plant behaviour and communication. Ecol. Lett. 2008, 11, 727-739. [CrossRef]

12. Dubnau, J.; Chiang, A.; Tully, T. Neural substrates of memory: From synapse to system. Neurobiology 2003, 54, 238-253. [CrossRef] [PubMed]

13. Schultz, W.; Dayan, P.; Montague, P. A neural substrate of prediction and reward. Science 1997, 275, 1593-1599. [CrossRef] [PubMed]

14. Michmizos, D.; Hilioti, Z. A roadmap towards a functional paradigm for learning \& memory in plants. Plant Physiol. 2019, 232, 209-215.

15. Shulaev, V.; Silverman, P.; Raskin, I. Airborne signalling by methyl salicylate in plant pathogen resistance. Nature 1997, 385, 718-721. [CrossRef]

16. Schramm, J. Temporal lobe epilepsy surgery and the quest for optimal extent of resection: A review. Epilepsia 2008, 49, 1296-1307. [CrossRef] [PubMed]

17. Johnston, K.; Ver Hoef, J.M.; Krivoruchko, K.; Lucas, N. Using ArcGIS Geostatistical Analyst; ESRI: Redlands, CA, USA, 2001.

18. Fry, J.; Xian, G.; Jin, S.; Dewitz, J.A.; Homer, C.G.; Yang, L.; Barnes, C.A.; Herold, N.D.; Wickham, J.D. Completion of the 2006 National Land Cover Database for the Conterminous United States. Photogramm. Eng. Remote Sens. 2011, 77, 858-864.

19. Anderson, M.A.; Burda, J.E.; Ren, Y.; Ao, Y.; O’Shea, T.M.; Kawaguchi, R.; Coppola, G.; Khakh, B.S.; Deming, T.J.; Sofroniew, M.V. Astrocyte scar formation aids central nervous system axon regeneration. Nature 2016, 532, 195-200. [CrossRef]

20. Dickinson, M.B.; Whigham, D.F.; Hermann, S.M. Tree regeneration in felling and natural treefall disturbances in a semideciduous tropical forest in Mexico. For. Ecol. Manag. 2000, 134, 137-151. [CrossRef]

21. Jackson, S.M.; Fredericksen, T.S.; Malcolm, J.R. Area disturbed and residual stand damage following logging in a Bolivian tropical forest. For. Ecol. Manag. 2002, 166, 271-283. [CrossRef]

22. Feldpausch, T.R.; Jirka, S.; Passos, C.A.M.; Jasper, F.; Riha, S.J. When big trees fall: Damage and carbon export by reduced impact logging in southern Amazonia. For. Ecol. Manag. 2005, 219, 199-215. [CrossRef]

23. Singh, S.K.; Hawkins, C.; Clarke, I.D.; Squire, J.A.; Bayani, J.; Hide, T.; Henkelman, R.M.; Cusimano, M.D.; Dirks, P.B. Identification of human brain tumour initiating cells. Nature 2004, 432, 396-401. [CrossRef] [PubMed]

24. Friedmann-Morvinski, D.; Bushong, E.A.; Ke, E.; Soda, Y.; Marumoto, T.; Singer, O.; Ellisman, M.H.; Verma, I.M. Dedifferentiation of neurons and astrocytes by oncogenes can induce gliomas in mice. Science 2012, 338, 1080-1084. [CrossRef] [PubMed]

(C) 2020 by the authors. Licensee MDPI, Basel, Switzerland. This article is an open access article distributed under the terms and conditions of the Creative Commons Attribution (CC BY) license (http://creativecommons.org/licenses/by/4.0/). 